E-JURNAL EKONOMI DAN BISNIS UNIVERSITAS UDAYANA
Available online at https://ojs.unud.ac.id/index.php/EEB/index
Vol. 10 No. 10, October 2021, pages: 873-882
e-ISSN: 2337-3067

\title{
PENGARUH KECUKUPAN MODAL, RISIKO OPERASIONAL DAN KREDIT BERMASALAH TERHADAP PROFITABILITAS PADA PERUSAHAAN PERBANKAN BUMN PERIODE 2010-2019
}

\author{
Septiani Ananda Putri ${ }^{1}$ Irvan Yoga Pardistya $^{2}$
}

\begin{tabular}{|c|c|}
\hline Article history: & Abstract \\
\hline $\begin{array}{l}\text { Submitted: } 23 \text { Februari } 2021 \\
\text { Revised: } 14 \text { April } 2021 \\
\text { Accepted: } 17 \text { Juni } 2021\end{array}$ & \multirow{2}{*}{$\begin{array}{l}\text { This study aims to determine the effect of capital adequacy, } \\
\text { operational risk and non-performing loans on profitability in state-owned } \\
\text { banks for the } 2010-2019 \text { period. This research uses purposive sampling } \\
\text { method by taking a sample of } 4 \text { banks taken from www.sahamok.net data. } \\
\text { The data is obtained from the annual financial reports issued by state- } \\
\text { owned banks by visiting the websites of each state-owned bank. The sample } \\
\text { size is } 32 \text { of the total sample obtained from } 4 \text { banks. The analysis technique } \\
\text { used in this research is multiple linear regression with a significance level } \\
\text { of } 5 \% \text {. The results of this study partially }(t \text { test) show that Capital Adequacy } \\
\text { (CAR) and Non-Performing Credit (NPL) have a positive and significant } \\
\text { effect on profitability, while Operational Risk (BOPO) has a negative and } \\
\text { significant effect on the profitability of BUMN banking in the 2010-2019 } \\
\text { period. Simultaneously (F test) the Capital Adequacy Ratio (CAR), } \\
\text { Operating Costs to Operating Income (BOPO) and Non-Performing Loans } \\
\text { (NPL) have the same effect on profitability. }\end{array}$} \\
\hline $\begin{array}{l}\text { Capital Adequacy; } \\
\text { Operational Risk; } \\
\text { Non Performing Loan; } \\
\text { Profitability; }\end{array}$ & \\
\hline Kata Kunci: & Abstrak \\
\hline $\begin{array}{l}\text { Universitas Singaperbangsa } \\
\text { Karawang, Jawa Barat, } \\
\text { Indonesial } \\
\text { Email: } \\
\text { 1710631030159@student.unsi } \\
\text { ka.ac.id }{ }^{1}\end{array}$ & $\begin{array}{l}\text { Penelitian ini bertujuan untuk mengetahui pengaruh kecukupan } \\
\text { modal, risiko operasional dan kredit bermasalah terhadap profitabilitas } \\
\text { pada perbankan BUMN periode 2010-2019. Penelitian ini menggunakan } \\
\text { metode purposive sampling dengan mengambil sampel sebanyak } 4 \text { bank } \\
\text { yang diambil dari data www.sahamok.net. Data diperoleh dari laporan } \\
\text { keuangan tahunan yang diterbitkan oleh bank-bank BUMN dengan } \\
\text { mengunjungi website masing-masing bank BUMN. Besar sampel adalah } \\
32 \text { dari total sampel yang diperoleh dari } 4 \text { bank. Teknik analisis yang } \\
\text { digunakan dalam penelitian ini adalah regresi linier berganda dengan taraf } \\
\text { signifikansi 5\%. Hasil penelitian ini secara parsial (uji t) menunjukkan } \\
\text { bahwa Kecukupan Modal (CAR) dan Kredit Bermasalah (NPL) } \\
\text { berpengaruh positif dan signifikan terhadap profitabilitas, sedangkan } \\
\text { Risiko Operasional (BOPO) berpengaruh negatif dan signifikan terhadap } \\
\text { profitabilitas. Perbankan BUMN periode 2010-2019. Secara simultan (uji } \\
\text { F) Rasio Kecukupan Modal (CAR), Biaya Operasional terhadap } \\
\text { Pendapatan Operasional (BOPO) dan Kredit Bermasalah (NPL) } \\
\text { berpengaruh sama terhadap profitabilitas (ROA). }\end{array}$ \\
\hline
\end{tabular}

Universitas Singaperbangsa Karawang, Jawa Barat, Indonesia ${ }^{2}$

Email: irvan.yoga@fe.unsika.ac.id ${ }^{2}$ 


\section{PENDAHULUAN}

Perbankan menjadi salah satu tumpuan perekonomian suatu negara, karena fungsinya sebagai penghubung antara penyedia dana dan pengguna dana. Agar dapat melindungi kepercayaan masyarakat, perbankan perlu menjaga kinerja keuangannya. Penilaian kinerja yang baik dalam suatu lembaga atau perusahaan dapat menggunakan berbagai indikator, salah satunya dengan menilai laporan keuangan untuk mengetahui tingkat profitabilitasnya. Menurut Kasmir (2016) menjelaskan rasio profitabilitas yaitu rasio dalam menghitung kesanggupan perusahaan memperoleh keuntungannya. Rasio inilah yang biasanya dilihat oleh investor, karena perhatian utamanya adalah kesanggupan perusahaan dalam memperoleh keuntungannya. Penelitian ini memakai perhitungan rasio Return On Asset, ROA dipakai dalam menilai efisiensi manajemen untuk mendapatkan pengembalian atas penggunaan aset perusahaan. Besarnya ROA akan meningkatkan keuntungan yang didapatkan oleh bank, serta membuat posisi bank pada aspek penggunaan aset semakin baik serta terjadi peningkatan pada kinerja keuangan perbankan. Dampak baik atau buruk kinerja keuangan bank dipengaruhinya oleh berbagai faktor. Faktor yang digunakan pada penelitian adalah rasio kecukupan modal, risiko operasional dan kredit bermasalah.

Perbankan dengan modal yang cukup akan menjalankan kegiatan usahanya dengan baik serta akan memberikan keuntungannya terhadap bank tersebut. Dalam penelitian kecukupan modal dihitung menggunakan rasio Capital Adequacy Rasio. Besarnya nilai CAR pada laporan keuangan menggambarkan posisi perbankan yang baik. Berdasarkan Peraturan Otoritas Jasa Keuangan Nomor 11/POJK.03/2016) tentang kewajiban penyediaan modal minimum bank umum, rasio modal inti minimum sebesar $8 \%$ dari ATMR menurut risiko. Rasio CAR diatas $8 \%$ menandakan kesanggupan bank untuk bertanggungjawab atas risiko yang timbul. Pada penelitian Putri et al., (2018) membuktikannya CAR pengaruhnya positif serta signifikan terhadap profitabilitas (ROA). Penelitiannya R. Putri \& Dewi (2017) membuktikannya CAR secara parsial pengaruhnya positif serta signifikan terhadap profitabilitas. Penelitiannya Wahyuni Pratiwi \& Wiagustini (2016) membuktikannya Capital Adequacy Rasio pengaruhnya negatif serta tidak signifikan terhadap profitabilitas. H1 : Kecukupan Modal atau Capital Adequacy Ratio (CAR) berpengaruh positif dan signifikan terhadap profitabilitas.

Pengembangan industri perbankan, khususnya produk dan layanan yang semakin maju serta diversifikasi akan menambah pengaruh risiko didalam perbankan. Risiko yang terjadi dalam perbankan akan mempengaruhi kondisi perbankan tersebut dan berdampak pada kinerja keuangan bank. Tentunya semua bank menghapi berbagai risiko dalam merealisasikan profitabilitas, oleh karenanya bank diharuskan melaksanaka manajemen risiko yang efektif. MenurutSupriyono (2016) menjelaskan risiko operasional sebagai risiko kerugian yang ditimbulkan akibat ketidakcukupan atau kegagalan internal, manusia, sistem atau peristiwwa-peristiwa yang berasal dari luar (pihak eksternal). Perhitungan risiko operasional pada penelitian memakai rasio Biaya Operasional Pendapatan Operasional (BOPO). Pada penelitiannya Wayan \& Capriani (2016) membuktikannya bahwa BOPO pengaruhnya negatif signifikan terhadap profitabilitas. Penelitiannya R. Putri \& Dewi (2017) membuktikannya BOPO pengaruhnya negatif serta signifikan terhadap profitabilitas. H2 : Risiko Operasional atau Biaya Operasional terhadap Pendapatan Operasional (BOPO) berpengaruh negatif dan signifikan terhadap profitabilitas.

Tujuan utama memberikan kredit kepada debitur adalah agar debitur dapat memberikan kompensasi berupa bunga dalam jangka waktu yang disepakati untuk melunasi seluruh pinjamannya, namun tidak ada bank yang memiliki kredit lancar. Kredit bermasalah mengacu pada situasi di mana nasabah tidak dapat membayar hutangnya kepada bank seperti yang dijanjikan. Menurut Supriyono (2016), kredit bermasalah diartikan sebagai risiko kredit dimana penerima pinjaman atau penerbit 
suatu instrumen keuangan menolak atau tidak mampu membayar bunga atau melunasi pinjaman, sehingga menimbulkan kerugian ekonomi bagi bank. Penilaian kredit bermasalah pada penelitian ini menggunakan perhitungan Non Performing Loan yang digunakan untuk menilai kesanggupan bank dalam membayar debitur dalam mengembalikan risiko kredit. Kredit bermasalah sendiri memiliki korelasi negatif dengan perubahan pendapatan. Jika rasio kredit bermasalah meningkat maka laba akan turun, sehingga perubahan laba juga akan turun, begitu pula sebaliknya. Pada Penelitian Fajari \& Sunarto (2017) menjelaskan NPL pengaruhnya positif signifikan terhadap profitabilitas. Penelitiannya R. Putri \& Dewi (2017) memaparkan NPL pengaruhnya negatif serta signifikan terhadap profitabilitas. Penelitiannya Stanley et al., (2020) mendapatkan hasil bahwa NPLberpengaruh negatif dan signifikan terhadap profitabilitas. H3 : Kredit bermasalah atau Non Performing Loan (NPL) berpengaruh negatif dan signifikan terhadap profitabilitas.

Tujuan penelitian yakni untuk melihat apakah terdapat pengaruh antara kecukupan modal, risiko operasional dan kredit bermasalah terhadap profitabilitas pada perusahaan perbankan BUMN periode 2010-2019.

\section{METODE PENELITIAN}

Jenis penelitiannya adalah metode kuantitatif. Data kuantitatif pada penelitian yakni laporan keuangan tahunan yang diterbitkan perusahaan perbankan BUMN periode 2010-2019. Jenis datanya yakni data sekunder, sumber data diakses dari situs resmi perbankan BUMN. Populasi penelitiannya adalah Perusahaan Perbankan BUMN di Indonesia periode 2010-2019. Peneliti menggunakannya teknik Purposive Sampling untuk menentukan sample penelitiannya. Metode analisis data yang digunakannya adalah statistik deskriptif, uji asumsi klasik (uji normalitas, uji multikolinieritas, uji heterokedastisitas dan uji korelasi), analisis regresi linier berganda, koefisien determinasi (R2) dan uji hipotesis (uji t dan uji F) dengan menggunakan aplikasi SPPSS versi 25.

Tabel 1.

Sampel Penelitian

\begin{tabular}{cc}
\hline No. & Nama Perusahaan Perbankan BUMN \\
\hline 1 & PT. Bank Rakyat Indonesia \\
2 & PT. Bank Negara Indonesia \\
3 & PT. Bank Tabungan Negara \\
4 & PT. Bank Mandiri \\
\hline Sumber: Data Publikasi sahamoknet, 2020
\end{tabular}

Sumber: Data Publikasi sahamok.net, 2020

HASIL DAN PEMBAHASAN

Tabel 2.

Hasil Statistik Deskriptif

\begin{tabular}{|c|c|c|c|c|c|}
\hline & $\mathrm{N}$ & Minimum & Maximum & Mean & Std. Deviation \\
\hline X1_CAR & 32 & 14,64 & 22,96 & 18,6466 & 2,43591 \\
\hline X2_BOPO & 32 & 59,93 & 98,12 & 72,9047 & 8,90995 \\
\hline X3_NPL & 32 &, 37 & 4,78 & 1,7519 & 1,28057 \\
\hline Y_ROA & 32 &, 13 & 5,15 & 2,9072 & 1,14160 \\
\hline Valid N (listwise) & 32 & & & & \\
\hline
\end{tabular}

Sumber: Data diolah dengan SPSS 25, 2020

Pengaruh Kecukupan Modal, Risiko Operasional Dan Kredit Bermasalah Terhadap Profitabilitas Pada 
Pada hasil penelitiannya terlihat bahwa rata-rata CAR (X1) adalah 18,6466 dan standar deviasi 2,43591. CAR (X1) yang dimiliki BTN pada tahun 2014 adalah 14,64 dan CAR maksimum yang dimiliki oleh BRI pada tahun 2017 adalah 22,96. Nilai rata-rata BOPO (X2) adalah 72,9047 dan standar deviasinya 8,90995. Nilai minimum dipeoleh Bank Rakyat Indonesia tahun 2012 adalah 59,93 dan nilai maksimumnya diperoleh Bank Tabungan Negara pada tahun 2019 adalah 98,12. Nilai minimum NPL (X3) sebesar 0,37 diperoleh Bank Mandiri pada tahun 2012 serta nilai maksimumnya oleh BTN pada tahun 2019 sebesar 4,78. Rata-rata NPL (X3) yaitu 2,9072 dengan standar deviasi sebesar 1,14160. Standar deviasi profitabilitas adalah 1,14160 atau 1,14\%, dan rata-rata 2,9072 atau 2,90\%. Laba terendah dimiliki BTN tahun 2019 sebesar 0,13\% dan BRI tahun 2012 memiliki nilai laba tertinggi sebesar 5,15\%.

Tabel 3.

Hasil Kolmogorov-Smirnov

\begin{tabular}{|c|c|c|}
\hline \multicolumn{3}{|c|}{ Unstandardized Residual } \\
\hline $\mathrm{N}$ & & 32 \\
\hline \multirow{2}{*}{ Normal Parameters ${ }^{\mathrm{a}, \mathrm{b}}$} & Mean & ,0000000 \\
\hline & Std. Deviation & ,29250325 \\
\hline \multirow[t]{3}{*}{ Most Extreme Differences } & Absolute &, 077 \\
\hline & Positive & ,077 \\
\hline & Negative &,- 053 \\
\hline Test Statistic & &, 077 \\
\hline Asymp. Sig. (2-tailed) & &, $200^{\mathrm{c}, \mathrm{d}}$ \\
\hline
\end{tabular}

Sumber: Data diolah dengan SPSS 25, 2020

Pada Tabel 3. besarnya hasil uji Kolmogorov-Smirnov yang digunakan yakni 0,200. Membuktikan Asymp. Sig (2-tailed) bernilai lebih besar 0,05 artinya $\mathrm{H}_{0}$ diterima, artinya data yang digunakannya pada penelitian terdistribusi normal. Kesimpulannya adalah model regresi memenuhi asumsi normalitas.

Tabel 4.

Hasil Uji Multikolinieritas

\begin{tabular}{llcr}
\hline & \multicolumn{3}{c}{ Collinearity Statistics } \\
Model & & Tolerance & VIF \\
\hline 1 & X1_CAR &, 992 & 1,008 \\
& X2_BOPO &, 441 & 2,267 \\
& X3_NPL &, 444 & 2,255 \\
\hline
\end{tabular}

Sumber: Data diolah dengan SPSS 25, 2020

Hasil pada Tabel 4. menghasilkan VIF (Variance Inflation Factor) CAR (X1) sebesar 1,008 dengan nilai tolerance 0,992. Sedangkan BOPO (X2) memiliki nilai tolerance 0,441 serta nilai VIFnya sebesar 2,267 dan untuk NPL (X3) nilai tolerancenya yakni 0,444 sserta nilai VIF sebesar 2,255. Semua nilai variabel independennya kurang dari 10 serta nilai toleransinya $>0,1$ disimpulkan bahwa variabel independennya tidak memiliki multikolinearitas.

Hasil Tabel 5. semua variabel bebas yakni Capital Adequacy Rasio, Biaya Operasional Pendapatan Operasional dan Non Performing Loan menunjukkan hasil signifikan > 0,05 atau lebih besar dari 5\%. Kesimpulannya bahwa hasil pada penelitian ini tidak terjadinya heteroskedastisitas. 
Tabel 5.

Hasil Uji Heteroskedastisitas

\begin{tabular}{|c|c|c|c|c|c|c|}
\hline & \multirow[b]{2}{*}{ Model } & \multicolumn{2}{|c|}{ Unstandardized Coefficients } & \multirow{2}{*}{$\begin{array}{c}\text { Standardized } \\
\text { Coefficients } \\
\text { Beta } \\
\end{array}$} & \multirow[b]{2}{*}{$\mathrm{t}$} & \multirow[b]{2}{*}{ Sig. } \\
\hline & & $\mathrm{B}$ & Std. Error & & & \\
\hline \multirow[t]{4}{*}{1} & (Constant) &, 811 & ,429 & & 1,890 & ,069 \\
\hline & X1_CAR &,- 006 & ,013 &,- 080 &,- 446 & ,659 \\
\hline & X2_BOPO &,- 007 &, 005 &,- 341 & $-1,263$ &, 217 \\
\hline & X3_NPL & 005 & 036 & 034 &, 127 & 900 \\
\hline
\end{tabular}

Sumber: Data diolah dengan SPSS 25, 2020

Tabel 6.

Hasil Uji Autokorelasi

\begin{tabular}{|c|c|c|c|c|c|}
\hline \multirow[b]{2}{*}{ Model } & \multirow[b]{2}{*}{$\mathrm{R}$} & \multirow[b]{2}{*}{ R Square } & \multicolumn{3}{|c|}{ Std. Error of the } \\
\hline & & & Adjusted R Square & Estimate & Durbin-Watson \\
\hline 1 &, $967^{\mathrm{a}}$ & ,934 & ,927 & ,30777 & ,895 \\
\hline
\end{tabular}

Sumber: Data diolah dengan SPSS 25, 2020

Hasil perhitungan Tabel 6. membuktikan Durbin Watson dengan nilai 0.895, kemudian hasil dibandingkannya dengan nilai dl dan dua pada Tabel Durbin-Watson. Jumlah sampel pada penelitian ini sebanyak 32 sampel, dengan variabel bebas 3 maka didapatkan nilai dU sebesar 1.6505. Syarat pada penelitian yang dinyatakan tidak memiliki autokorelasi yaitu $\mathrm{dU}<\mathrm{d}<(4-\mathrm{dU})$, didapatkan hasil $1.6505>0.895<2.3495$ artinya terdapat autokorelasi pada model regresi yang digunakannya pada penelitian.

Tabel 7.

Hasil Analisis Regresi Linier Berganda

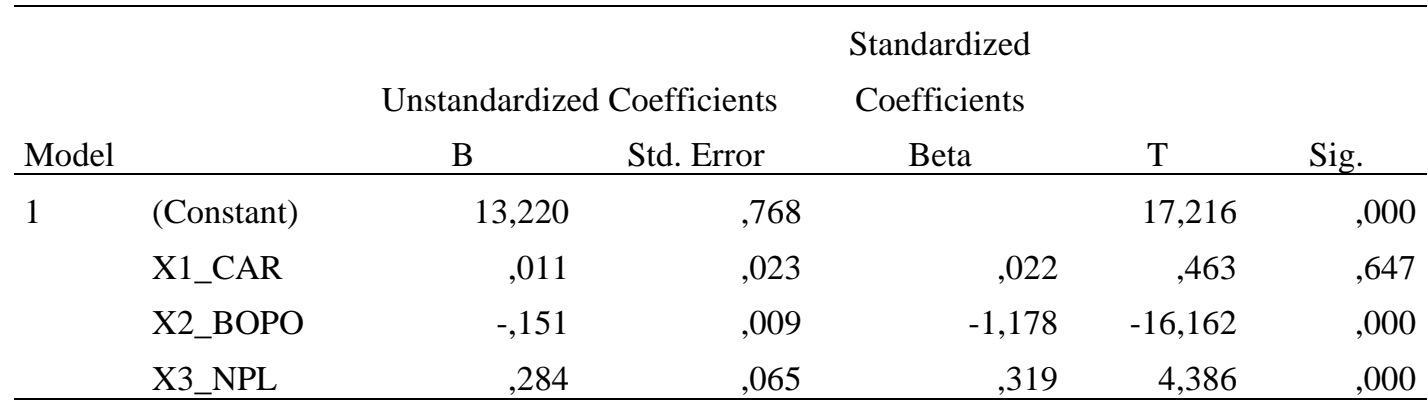

Sumber: Data diolah dengan SPSS 25, 2020

Hasil Tabel 7. terlihat persamaan regresi linier berganda adalah:

$$
\mathrm{Y}=13.220+0.11 \mathrm{X} 1-0.151 \mathrm{X} 2+0.284 \mathrm{X} 3+\mathrm{e}
$$

Keterangan:

$\mathrm{Y} \quad=$ Profitabilitas (Return On Asset)

Pengaruh Kecukupan Modal, Risiko Operasional Dan Kredit Bermasalah Terhadap Profitabilitas Pada Perusahaan Perbankan BUMN Periode 2010-2019, Septiani Ananda Putri dan Irvan Yoga Pradstya 
$\alpha \quad=$ Konstanta

$\beta_{1} \quad=$ Koefisien regresi Kecukupan Modal $\left(\mathrm{X}_{1}\right)$

$\beta_{2} \quad=$ Koefisien regresi Risiko Operasional $\left(X_{2}\right)$

$\beta_{3} \quad=$ Koefisien regresi Kredit Bermasalah $\left(\mathrm{X}_{3}\right)$

$\mathrm{X}_{1} \quad=$ Kecukupan Modal

$\mathrm{X}_{2} \quad=$ Risiko Operasional

$\mathrm{X}_{3} \quad=$ Kredit Bermasalah

e $\quad=$ Standar Error

Terlihat nilai konstantanya sebesar 13.220 yang artinya apabila seluruh variabel (kecukupan modal, risiko operasional dan kredit bermasalah) dianggap konstan maka nilai profitabilitasnya akan meningkat sebesar 13.220. Koefisien kecukupan modal (X1) senilai 0.011, berarti jika nilai CAR bertambah satu persen maka profitabilitasnya meningkat senilai 0.011 atau sebaliknya. Nilai koefisien risiko operasional (BOPO) sebesar 0.151, artinya jika nilai risiko operasional (BOPO) mengalami penambahan satu persen maka profitabilitasnya (ROA) menurun sebesar -0.151 atau sebaliknya. Sedangkan pada nilai koefisien kredit bermasalah (X3) sebesar 0.284 , artinya jika nilai kredit bermasalah (NPL) mengalami peningkatan sebesar 0,284 maka profitabilitasnya (Return On Asset) akan terjadi kenaikan sebesar 0.284 atau sebaliknya.

Tabel 8.

Hasil Uji Koefisien Determinasi

\begin{tabular}{|c|c|c|c|c|c|}
\hline Model & $\mathrm{R}$ & R Square & $\begin{array}{l}\text { Adjusted R } \\
\text { Square }\end{array}$ & $\begin{array}{l}\text { Std. Error of the } \\
\text { Estimate }\end{array}$ & Durbin-Watson \\
\hline 1 & ,967 & ,934 & ,927 & 30777, & 89 \\
\hline
\end{tabular}

Sumber: Data diolah dengan SPSS 25, 2020

Hasil pengujian Tabel 8, membuktikan Adjusted R-square senilai 0,927 atau 92,7\%. Artinya profitabilitas (Y) dipengaruhi oleh 92,7\% rasio kecukupan modal (CAR), risiko operasional (BOPO) dan kredit bermasalah (NPL). Nilai tersebut menunjukkan bahwa secara keseluruhan variabel independennya mempengaruhi 92,7\% variabel dependen, sedangkan 7,3\% dipengaruhi variabel lain diluar penelitian.

Tabel 9.

Hasil Uji F

\begin{tabular}{lrrrrrr}
\hline Model & & Sum of Squares & df & Mean Square & F & Sig. \\
\hline 1 & Regression & 37,748 & 3 & 12,583 & 132,835 &, $000^{\mathrm{b}}$ \\
& Residual & 2,652 & 28 &, 095 & & \\
& & & & & &
\end{tabular}

Sumber: Data diolah dengan SPSS 25, 2020

Hasil pengujiannya menunjukkan nilai signifikan uji $\mathrm{F}$ senilai $0,000<0,05$ artinya rasio kecukupan modal, risiko operasional dan kredit bermasalah memiliki pengaruh yang sama terhadap profitabilitas. Dapat dikatakan penelitian tersebut lolos dalam uji kelayakan model sebagai model regresi. Artinya terdapat 
pengaruh variabel bebas yaitu Capital Adequacy Rasio, BOPO dan NPL secara simultan terhadap variabel terikat profitabilitas (ROA).

Uji t dipergunkannya untuk mengetahui apakah Capital Adequacy Rasio(X1), BOPO(X2) dan Non Performing Loan(X3) dampaknya signifikan terhadap profitabilitas (Y). Hasil pengujian Tabel diatas, memperlihatkan hasil nilai signifikan rasio kecukupan modal yakni 0,647 >0,05. Hal ini menunjukkannya hasil signifikan lebih besar daripada taraf signifikan yakni 0,05, disimpulkannya kecukupan modal diwakili oleh CAR tidak memiliki pengaruh terhadap profitabilitas. Nilai $\beta$ sebesar 0,011 menunjukkan arah positif yang menandakan rasio kecukupan modal berpengaruh positif terhadap profitabilitas. Menunjukkan nilai rasio kecukupan modal mengalami peningkatan, maka profitabilitasnya bank akan meningkat, atau sebaliknya.

Tabel 10.

Hasil Uji t

\begin{tabular}{llrrrrr} 
& \multicolumn{7}{c}{ Standardized } \\
Model & & Unstandardized Coefficients & Coefficients & & \\
\hline 1 & B & Std. Error & Beta & \multicolumn{1}{c}{ T } & \multicolumn{1}{c}{ Sig. } \\
& (Constant) & 13,220 &, 768 & & 17,216 &, 000 \\
& X1_CAR &, 011 &, 023 &, 022 &, 463 &, 647 \\
& X2_BOPO &,- 151 &, 009 & $-1,178$ & $-16,162$ &, 000 \\
& X3_NPL &, 284 &, 065 &, 319 & 4,386 &, 000 \\
\hline
\end{tabular}

Sumber: Data diolah dengan SPSS 25, 2020

Pada uji t yang kedua, yaitu pengujian pengaruh risiko operasional atau BOPO (X2) terhadap profitabilitas atau ROA (X3). Besarnya nilai koefisien ( $\beta$ ) yaitu $-0,151$ menunjukkan arah negatif yang artinya risiko operasional pengaruhnya negatif terhadap profitabilitas. Nilai tersebut menandakan jika nilai rasio risiko operasional (BOPO) meningkat maka profitabilitas perbankan BUMN akan terjadi penurunan, begitu pula sebaliknya. Sedangkan nilai signifikannya yakni 0.000 , hasilnya lebih kecil daripada $\alpha=0,05$. Kesimpulannya adalah rasio BOPO yang digunakan untuk menghitung risiko operasional berpengaruh negatif dan signifikan terhadap profitabilitas atau Return On Asset.

Selanjutnya hasil pengujian pengaruh kredit bermasalah (NPL) sebagai variabel X3 terhadap profitabilitas (ROA) sebagai variabel Y, memperoleh nilai signifikan sebesar 0,000 atau lebih kecil dari taraf signifikan $\alpha=0,05$ atau 5\%. Dengan nilai koefisien $(\beta)$ senilai 0,284 yang mengunjukkan arah positif, maka dapat disimpulkan bahwa X3 atau kredit bermasalah yang dihitung menggunakan NPL dampaknya positif dan signifikan terhadap profitabilitas yang dihitung dengan ROA.

Tingginya nilai CAR dalam laporan keuangan, akan meningkatkannya nilai profitabilitas pada perbankan, ataupun rendahnya nilai CAR akan semakin rendah pula nilai profitabilitasnya. Pada hipotesis 1 mengatakan kecukupan modal atau CAR berpengaruh positif dan signifikan terhadap profitabilitas (ROA). Hasil pengujian uji $\mathrm{t}$ diperoleh nilai koefisien regresi $(\beta)$ 0,011 dan tingkat signifikan 0,647 . Nilai signifikan menunjukkan hasil lebih besar dari taraf signifikan $\alpha=0,05$ kesimpulannya yaitu rasio Capital Adequacy Ratio berpengaruh positif dan signifikan terhadap profitabilitas yang dihitung menggunakan ROA sehingga H1 dapat diterima. Penelitian ini mendapatkan hasil yang sama dengan penelitiannya Putri, dkk (2018) yang membuktikannya bahwa CAR pengaruhnya positif serta signifikan terhadap profitabilitas dan sesuai dengan hasil penelitiannya Rosana Nur \& Sayu Kt (2017) yang mendapatkan hasil CAR pengaruhnya positif dan signifikan terhadap profitabilitas. Walaupun hasil penelitian tidak sesuai dengan penelitiannya dari Luh Putu Sukma \& Ni Putu Wiagustini (2016) memperoleh hasil CAR dampaknya negatif tidak signifikan terhadap profitabilitas.

Pengaruh Kecukupan Modal, Risiko Operasional Dan Kredit Bermasalah Terhadap Profitabilitas Pada 
Risiko operasional pada penelitian menggunakan pengukuran perbandingan biaya operasional pendapatan operasional (BOPO). Besarnya nilai BOPO akan menurunkan nilai profitabilitas (ROA), atau sebaliknya semakin rendah nilai BOPO akan meningkatkan nilai profitabilitas. Dalam penjelasan hasil penelitian mengenai pengaruh risiko operasional (BOPO) terhadap profitabilitas (ROA), $\mathrm{H} 2$ dalam penelitian membuktikan risiko operasional pengaruhnya negatif dan signifikan terhadap profitabilitas. Hasilnya Tabel uji t diperolehnya nilai signifikan senilai 0,000 dengan nilai koefisien $(\beta)$ BOPO sebesar $-0,151$. Nilai signifikan yang didapatkan BOPO pada penelitian lebih kecil daripada taraf signifikan $\alpha=0,05$ atau 5\% kesimpulannya ada risiko operasional (BOPO) pengaruhnya negatif dan signifikan terhadap profitabilitas (ROA) maka hipotesis 2 diterima. Penelitian ini sependapat dengan hasil penelitiannya Rosana Nur \& Sayu Kt. (2017) yang mendapatkan hasil BOPO pengaruhnya negatif serta signifikan terhadap profitabilitas.

Penjelasan pada hasil penelitian mengenai pengaruhnya kredit bermasalah (NPL) terhadap profitabilitas (ROA), hipotesis 3 penelitian ini mengatakan kredit bermasalah berpengaruh negatif dan signifikan terhadap profitabilitas. Hasilnya pada Tabel 10. uji t membuktikannya nilai koefisien ( $\beta$ ) yakni 0,284 dan nilai signifikan 0,000 , hasil nilai signifikan yang didapat lebih kecil daripada taraf signifikan $\alpha=0,05$ dan nilai koefisien yang menunjukkan arah positif. Kesimpulannya yang didapatkan bahwa kredit bermasalah yang dihitung dengan NPL berpengaruh positif dan signifikan terhadap profitabilitas dihitung dengan ROA, maka H3 ditolak. Penelitan ini tidak sejalur dengan penelitiannya Josua, dkk (2020) memperoleh hasil NPL pengaruhnya negatif serta signikan terhadap profitabilitas, tetapi sesuai dengan penelitiannya Slamet Fajari dan Sunarto (2017) membuktikan NPL pengaruhnya positif serta signifikan terhadap profitabilitas. Kredit bermasalah (NPL) dipakai dalam menilai kemampuan perbankan dalam membayar kembali debitur untuk membayar risiko kredit. Jika nilai rasio kredit bermasalah yang tinggi maka akan menurunkan labanya, ataupun jika risiko kredit menurun maka akan meningkatkan nilai laba.

\section{SIMPULAN DAN SARAN}

Berdasarkan hasil pembahasan yang telah diuraikan, dapat disimpulkan bahwa, rasio kecukupan modal (CAR) memiliki pengaruh positif dan tidak signifikan terhadap profitabilitas (ROA) perusahaan perbankan BUMN. Meningkatnya permodalan perbankan BUMN maka semakin tinggi pula tingkat keuntungannya. Oleh karena itu, jika tingkat permodalannya tinggi maka bank berplat merah tersebut dapat menyediakan dana untuk kegiatan usahanya, dan profitabilitas bank BUMN tersebut akan semakin meningkat. Biaya Operasional terhadap Pendapatan Operasional (BOPO) memiliki pengaruh negatif signifikan terhadap profitabilitas (ROA) perusahaan perbankan BUMN. Hal ini menjelaskan bahwa BOPO bertambah maka profitabilitas (ROA) pada penelitian ini akan mengalami penurunan, ataupun sebaliknya semakin rendahnya nilai BOPO maka akan meningkatkan perolehan laba pada perbankan BUMN. Non Performing Loan (NPL) memiliki pengaruh positif dan signifikan terhadap profitabilitas (ROA) pada perusahaan perbankan BUMN, meningkatnya nilai kredit bermasalah akan mengurangi modal yang dimiliki perbankan BUMN. Hal ini dikarenakan modal tersebut digunakan untuk menutupi besarnya nilai kredit bermasalah, sehingga akan mengurangi kepercayaan masyarakat terhadap bank milik negara tersebut. Sedangkan pada uji F ketiga variabel (Kecukupan Modal, Risiko Operasional dan Kredit Bermasalah) memiliki pengaruh yang sama terhadap profitabilitas.

Berdasarkan kesimpulan yang telah diuraikan, disarankan untuk perbankan BUMN, Capital Adequacy Rasio (CAR) berpengaruh positif dan tidak signifikan, maka disarankan agar memelihara dan menjaga kecukupan modal dasarnya. Biaya Operasional terhadap Pendapatan Operasional (BOPO) disarankan agar perbankan BUMN lebih menjaga efisiensi bank dengan mengelola biaya operasional sehingga pengeluarannya lebih rendah dari pendapatan operasional, sedangkan untuk Non Performing Loan (NPL) disarankan perbankan BUMN agar lebih berhati-hati dalam melakukan pembinaan dan pengelolaan kredit. Untuk peneliti selanjutnya, keterbatasan dari penelitian ini adalah 
peneliti hanya meneliti variabel Capital Adequacy Rasio (CAR), Biaya Operasional terhadap Pendapatan Operasional (BOPO), Non Performing Loan (NPL) dan Return On Asset (ROA). Disarankan kepada peneliti selanjutnya agar dapat meneliti variabel-variabel lain diluar penelitian ini, seperti variabel Loan to Deposit Rasio, Net Intersert Margin, Cash Turn Over dan Dept to Equity Rasio serta diharakan mampu menambah referensi terhadap variabel-variabel yang diteliti..

\section{REFERENSI}

Dewi, A. S. (2018). Pengaruh CAR, BOPO, NPL, NIM, dan LDR terhadap ROA pada Perusahaan di Sektor Perbankan yang Terdaftar di BEI Periode 2012-2016. Jurnal Pundi, 1(3), 223-236. https://doi.org/10.31575/jp.v1i3.55

Fajari, S., \& Sunarto. (2017). Pengaruh CAR, LDR, NPL, BOPO terhadap Profitabilitas Bank (Studi Kasus Perusahaan Perbankan yang Tercatat di Bursa Efek Indonesia Periode Tahun 2011 sampai 2015). Prosiding Seminar Nasional Multi Disiplin Ilmu \& Call for Papers UNISBANK Ke-3, 3(3), 853-862.

Ghozali, I. (2018). No Title. In Aplikasi Analisis Multivariate Dengan Program IBM SPSS 25 Edisi 9. Universitas Diponegoro.

Kasmir. (2016). No Title. In Analisis Laporan Keuangan Edisi Pertama Cetakkan Kesembilan. RadjaGrafindo Persada.

Mosey, A. C., Tommy, P., \& Untu, V. (2018). Pengaruh Risiko Pasar Dan Risiko Kredit Terhadap Profitabilitas Pada Bank Umum Bumn Yang Terdaftar Di Bei Periode 2012-2016. Jurnal EMBA: Jurnal Riset Ekonomi, Manajemen, Bisnis Dan Akuntansi, 6(3), 1338-1347. https://doi.org/10.35794/emba.v6i3.20217

Parenrengi, S., \& Hendratni, T. W. (2018). Pengaruh dana pihak ketiga, kecukupan modal dan penyaluran kredit terhadap profitabilitas bank. Jurnal Manajemen Strategi Dan Aplikasi Bisnis, 1(1), 9-18. https://doi.org/10.36407/jmsab.v1i1.15

Pinasti, W. F., \& Mustikawati, R. I. (2018). Pengaruh Car, Bopo, Npl, Nim Dan Ldr Terhadap Profitabilitas Bank Umum Periode 2011-2015. Nominal, Barometer Riset Akuntansi Dan Manajemen, 7(1). https://doi.org/10.21831/nominal.v7i1.19365

POJK Nomor 11/POJK.03/2016, Tentang Kewajiban Penyediaan Modal Minimum Bank Umum

Prasetyo, D., \& Darmayanti, N. (2015). Pengaruh Risiko Kredit, Likuiditas, Kecukupan Modal, Dan Efisiensi Operasional Terhadap Profitabilitas Pada Pt Bpd Bali. E-Jurnal Manajemen Universitas Udayana, 4(9), 253-294.

Putri, N. K. A. P., Wiagustini, L. P., \& Abundanti, N. N. (2018). Pengaruh Npl, Car Dan Bopo Terhadap Profitabilitas Pada Bpr Di Kota Denpasar. E-Jurnal Manajemen Universitas Udayana, 7(11), 6212. https://doi.org/10.24843/ejmunud.2018.v07.i11.p15

Putri, R., \& Dewi, S. (2017). Pengaruh Ldr, Car, Npl, Bopo terhadap Profitabilitas Lembaga Perkreditan Desa di Kota Denpasar. E-Jurnal Manajemen Universitas Udayana, 6(10), 250-565.

Riadi, S. (2018). The effect of Third Parties Fund, Non Performing Loan, Capital Adequacy Ratio, Loan to Deposit Ratio, Return On Assets, Net Interest Margin and Operating Expenses Operating Income on Lending (Study in Regional Development Banks in Indonesia). Proceedings of the International Conference on Industrial Engineering and Operations Management, 2018-March, 1015-1026.

Silaban, P. (2017). The Effect of Capital Adequacy Ratio, Net Interest Margin and Non-Performing Loans on Bank Profitability: The Case of Indonesia. International Journal of Economics and Business Administration, 5(3), 58-69. https://doi.org/10.35808/ijeba/135

Sitompul, S., \& Nasution, S. K. (2019). The Effect of Car, BOPO, NPF, and FDR on Profitability of Sharia Commercial Banks in Indonesia. Budapest International Research and Critics Institute (BIRCI-Journal): Humanities and Social Sciences, 2(3), 234-238. https://doi.org/10.33258/birci.v2i3.412

Stanley, J., Hutahaean, T. F., Uli, R., \& Sinaga, A. (2020). The Effect of CAR, NPL, LDR, and BOPO On ROA in Banking Companies Listed in Indonesia Stock Exchange Period 2011 - 2016. 2(5).

Sudarmawanti, E., \& Pramono, J. (2017). Pengaruh CAR, NPL, BOPO, NIM dan LDR Terhadap ROA (Studi Kasus Pada Bank Perkreditan Rakyat di Salatiga yang terdaftar di Otoritas Jasa Keuangan tahun 2011 2015). Among Makarti, 10(19), 1-18.

Sugiyono. (2017). No Title. In Metode Penelitian Kuantitatif Kualitatif dan R\&D. Alfabeta,CV.

Sugiyono. (2020). No Title. In Metode Penelitian Kuantitatif Kualitatif dan $R \& D$ Edisi Kedua Cetakan ke-2. Alfabeta,CV.

Supriyono, R. . (2016). No Title. In Manajemen Risiko. Gadjah Mada University Press.

Wahyuni Pratiwi, L., \& Wiagustini, N. (2016). Pengaruh Car,Bopo,Npl Dan Ldr Terhadap Profitabilitas. EJurnal Manajemen Universitas Udayana, 5(4), 255168.

Pengaruh Kecukupan Modal, Risiko Operasional Dan Kredit Bermasalah Terhadap Profitabilitas Pada

Perusahaan Perbankan BUMN Periode 2010-2019,

Septiani Ananda Putri dan Irvan Yoga Pradstya 
Wayan, N., \& Capriani, W. (2016). Fakultas Ekonomi dan Bisnis Universitas Udayana, Bali, Indonesia Fakultas Ekonomi dan Bisnis Universitas Udayana, Bali, Indonesia ABSTRAK PENDAHULUAN Bank merupakan suatu lembaga yang berfungsi sebagai perantara keuangan ( financial intermediary ) ant. 5(3), 1486-1512. 